\title{
Emotions During Sexual Activity: Differences Between Sexually Functional and Dysfunctional Men and Women
}

\author{
Pedro J. Nobre · José Pinto-Gouveia
}

Received: 23 April 2004 / Revised: 5 August 2005 / Accepted: 16 December 2005 / Published online: 15 August 2006

(C) Springer Science+Business Media, Inc. 2006

\begin{abstract}
The present study investigated the differences in emotional response to automatic thoughts presented during sexual activity between sexually functional and dysfunctional men and women. A total of 376 participants (160 women and 120 men without sexual problems and 47 women and 49 men with a DSM-IV-TR diagnosis of sexual dysfunction) completed the Sexual Modes Questionnaire (SMQ male and female versions; P. J. Nobre \& J. Pinto-Gouveia, 2000) and measures of sexual functioning: The International Index of Sexual Function (IIEF; R. C. Rosen et al., 1997), and The Female Sexual Function Index (FSFI; R. C. Rosen et al., 2000). The SMQ is a combined measure constituted by three interdependent subscales: Automatic Thought subscale (AT), Emotional Response subscale (ER), and Sexual Response subscale (SR). Emotions were assessed by the ER subscale, where participants endorsed emotional reactions (worry, sadness, disillusion, fear, guilt, shame, anger, hurt, pleasure, satisfaction) to a list of automatic thoughts (AT subscale) that may occur during sexual activity. Results showed that both men and women with sexual dysfunction had significantly less positive emotional reactions to auto-
\end{abstract}

\section{P. J. Nobre}

Departamento de Educação e Psicologia, Universidade de

Trás-os-Montes e Alto Douro,

Vila Real, Portugal

J. Pinto-Gouveia

Faculdade de Psicologia e Ciências da Educação,

Universidade de Coimbra,

Coimbra, Portugal

P. J. Nobre $(\bowtie)$

Rua Amorim de Carvalho, 97,

Senhora da Hora, 4460 Portugal

e-mail: pedro.j.nobre@clix.pt matic thoughts during sexual activity. Sexually dysfunctional men had significantly more emotions of sadness, disillusion, and fear, and less pleasure and satisfaction, compared to men without sexual problems. Women with sexual dysfunction had significantly less pleasure and satisfaction, and more sadness, disillusion, guilt, and anger. Findings were congruent with recent studies indicating that emotions related to depressed affect (sadness, disillusion, lack of pleasure) as opposed to negative emotions (mostly related to anxiety) were stronger correlates of sexual dysfunction.

Keywords Emotions · Depressed affect · Anxiety · Cognitions $\cdot$ Sexual dysfunction

\section{Introduction}

A growing body of literature has recently emerged on the role of emotions in sexual response. Studies on the effects of anxiety on sexual functioning have contradicted classic theoretical perspectives based on clinical observations (Kaplan, 1974; Masters \& Johnson, 1970). Contrary to the models of Masters and Johnson and Kaplan, results systematically suggest a neutral or even a facilitative effect of anxiety on both male and female sexual arousal (Barlow, Sakheim, \& Beck, 1983; Elliot \& O’Donohue, 1997; Hoon, Wincze, \& Hoon, 1977; Laan, Everaerd, Van-Aanhold, \& Rebel, 1993). Moreover, studies regarding the impact of sympathetic nervous system (SNS) activation (the physiological component of anxiety) have consistently indicated a facilitating effect on physiological sexual arousal, especially in women (Meston \& Gorzalka, 1996; Palace, 1995; Palace \& Gorzalka, 1990). 
This pattern is better observed in non-clinical populations compared to clinical samples. Although studies conducted on women with sexual dysfunction confirmed the facilitating effect of anxiety on sexual response (Meston \& Gorzalka, 1996; Palace, 1995; Palace \& Gorzalka, 1990), research with male clinical samples indicated a reverse pattern (Beck, Barlow, Sakheim, \& Abrahamson, 1987). One possible explanation for this contradiction relies on the different operational definitions of anxiety used in the male and female studies. Whereas Beck et al. (1987) used contingent and non-contingent electric shock threats during exposure to erotic films (measuring not only physiological dimensions-non contingent threat, but also cognitive dimensions-contingent threat to erectile response), studies with women only manipulated the SNS dimensions of anxiety.

Regarding the impact of mood, research consistently suggests that depressive affect is negatively related to sexual arousal. Heiman and Rowland (1983) and Beck and Barlow (1986) found that individuals with sexual dysfunction reported significantly less positive affect during exposure to erotica. Similarly, several studies have shown that positive affect and subjective sexual arousal are positively correlated in both men with and without sexual dysfunction during exposure to erotic films (Koukounas \& McCabe, 2001; Rowland, Cooper, \& Heiman, 1995; Rowland, Cooper, \& Slob, 1996). In a study conducted with sexually functional females, Heiman (1980) reported similar results. Moreover, Nobre et al. (2003), in a study on the determinants of male sexual arousal, found that low positive affect during sexual activity (assessed by the Positive Affect and Negative Affect Scales; Watson, Clark, \& Tellegen, 1988) was significantly associated with low subjective and physiological sexual arousal (erectile levels). Experimental studies have further supported these findings, showing that manipulated negative affect in sexually functional subjects produced a delay in subjective sexual arousal (Meisler \& Carey, 1991) and a decrease in penile tumescence (Mitchell, DiBartolo, Brown, $\&$ Barlow, 1998). Recently, Bancroft et al. (2003) examined the relation between mood and sexuality in men and found that $42 \%$ indicated decreased sexual interest when depressed (compared to $9.4 \%$ who indicated increased sexual interest), whereas when anxious/stressed, $20.6 \%$ indicated increased and $28.3 \%$ decreased sexual interest. Overall, these data seem to suggest that depressed mood (lack of positive affect) is more strongly associated with sexual response than anxiety states.

Studies on the impact of anger and worry on sexual functioning show inconsistent results. Yates, Barbaree, and Marshall (1984) examined the relation between anger and deviant sexual arousal and showed that this emotion might facilitate sexual arousal, whereas Bozman and Beck (1991) reported that anger decreased both desire and arousal. Katz and Jardine (1999) tested the relationship between worry as a trait of personality and sexual desire and aversion in a group of male and female students. Results indicated statistically significant correlations (although weak) between a predisposition to worry and sexual aversive behaviors and low sexual desire.

The aim of the present study was to assess the emotional reactions to a list of automatic thoughts presented to sexually functional and dysfunctional men and women during sexual activity. We used cognitive theory as a preferential framework to better understand the processes involved in sexual dysfunction. Of particular interest is Beck's (1996) modes model where the traditional central role of cognitive processing (mediating emotional and behavioral reactions) was substituted by a network of interdependent cognitive, emotional, and behavioral dimensions. Beck suggested that various psychopathological disorders could be conceptualized in terms of modes. For example, specific phobia could be characterized by specific dangerous thoughts, anxiety responses, and a behavioral impulse to escape, whereas depression could be characterized by loss thoughts accompanied by sadness and regressive behaviors.

For this purpose, we used the Sexual Modes Questionnaire (Nobre \& Pinto-Gouveia, 2000), a measure specifically designed to assess the interaction between automatic thoughts and related emotions and sexual responses during sexual activity. The SMQ consists of three interdependent subscales: an Automatic Thought subscale (AT), an Emotional Response subscale (ER), and a Sexual Response subscale (SR). For this particular study, we used the ER subscale where participants endorsed the emotional reactions (worry, sadness, disillusion, fear, guilt, shame, anger, hurt, pleasure, satisfaction) to a list of automatic thoughts (AT subscale) that may occur during sexual activity.

Previous research using the AT subscale has shown that men and women with sexual dysfunction had significantly more negative automatic thoughts during sexual activity compared to men and women without sexual difficulties (Nobre, 2003; Nobre \& Pinto-Gouveia, 2003b, 2004). Specifically, failure and disengagement thoughts, sexual abuse thoughts, and lack of erotic thoughts were more often endorsed by women with sexual dysfunction relative to controls whereas erection concern thoughts, failure anticipation thoughts, and lack of erotic thoughts were more often endorsed by men with sexual dysfunction compared to men without sexual difficulties (Nobre, 2003).

We predicted that sexually dysfunctional men and women would report significantly more negative emotions and less pleasure and satisfaction to automatic thoughts that occurred during sexual activity compared to men and women without sexual dysfunction. Specifically, and according to 
recent findings, we expected sexually dysfunctional men and women to report significantly more emotions associated with depressed mood (sadness, disillusion, guilt).

\section{Method}

\section{Participants}

A total of 376 subjects (207 women and 169 men) participated in the study: a clinical sample of 96 subjects (47 women and 49 men) and a control sample of 280 subjects (160 women and 120 men). The clinical sample was recruited from the sexology clinic of Coimbra's University Hospital. Participants diagnosed with sexual dysfunction, using the Diagnostic and Statistical Manual of Mental Disorders (DSM-IV-TR; American Psychiatric Association, 2000) criteria, constituted this clinical group. The principal diagnoses assigned were the following: for the men, erectile disorder $(69.4 \%)$, premature ejaculation $(22.4 \%)$, orgasmic disorder (4.1\%), hypoactive sexual desire (2\%), and sexual dysfunction not otherwise specified (2\%); for the women, hypoactive sexual desire $(40.4 \%)$, vaginismus (25.5\%), orgasmic disorders (21.3\%), dyspareunia (6.4\%), sexual arousal disorder (4.3\%), and sexual aversion disorder $(2.1 \%)$. A total of 21 women (43\%) and 9 men (18\%) had additional clinical diagnoses (secondary diagnosis). The clinical sample was obtained between September 2000 and December 2001 and the participation rate was $94.8 \%$. The demographic characteristics of the clinical sample are shown in Table 1.

Table 1 Demographic characteristics as a function of sex and group

\begin{tabular}{|c|c|c|c|c|}
\hline & \multicolumn{2}{|c|}{ Women } & \multicolumn{2}{|c|}{ Men } \\
\hline & $\begin{array}{l}\text { Clinical } \\
\text { sample } \\
(n=47)\end{array}$ & $\begin{array}{l}\text { Control } \\
\text { sample } \\
(n=160)\end{array}$ & $\begin{array}{l}\text { Clinical } \\
\text { sample } \\
(n=49)\end{array}$ & $\begin{array}{l}\text { Control } \\
\text { sample } \\
(n=120)\end{array}$ \\
\hline \multicolumn{5}{|l|}{ Age (in years) } \\
\hline$M$ & 28.7 & 30.4 & 43.0 & 39.2 \\
\hline$S D$ & 6.7 & 11.4 & 14.4 & 17.0 \\
\hline Range & $19-50$ & $18-75$ & $18-67$ & $18-79$ \\
\hline \multicolumn{5}{|l|}{ Marital status } \\
\hline Single (\%) & 23.4 & 57.5 & 26.5 & 39.0 \\
\hline Married/cohabiting (\%) & 70.2 & 36.9 & 71.4 & 55.1 \\
\hline $\begin{array}{l}\text { Divorced/separated/ } \\
\text { widowed }(\%)\end{array}$ & 6.4 & 5.6 & 2.0 & 5.9 \\
\hline \multicolumn{5}{|l|}{ Education level } \\
\hline $0-9$ years $(\%)$ & 27.7 & 10.7 & 75.5 & 17.1 \\
\hline $10-12$ years $(\%)$ & 31.9 & 24.5 & 22.4 & 17.1 \\
\hline$>13$ years $(\%)$ & 40.4 & 64.8 & 2.0 & 65.8 \\
\hline
\end{tabular}

Participants from the control sample were recruited with the help of volunteers in different regions of Portugal. In order to control for the presence of sexual dysfunction, controls who scored lower than the cutoffs on the different dimensions assessed by the International Index of Erectile Function (IIEF; Rosen et al., 1997) and the Female Sexual Function Index (FSFI; Rosen et al., 2000) were excluded. The cutoff scores used were the following: for the men, sexual desire $=5.2$, erectile function $=22$, orgasmic function $=5.9$, intercourse satisfaction $=7.7$, and overall satisfaction $=6.9$; for the women, sexual desire $=3.0$, sexual arousal $=4.1$, lubrication $=4.6$, orgasm $=3.8$, pain $=4.4$, and sexual satisfaction $=3.9$. With the exception of erectile function, where the optimal cutoff scores were calculated and published (Cappelleri, Rosen, Smith, Mishra, \& Osterloh, 1999), the remaining cutoff scores were based on average values on the different domains of the IIEF (Rosen et al., 1997) and FSFI (Rosen et al., 2000) from samples of subjects without any history of sexual dysfunction. The cutoff scores were calculated by subtracting one $S D$ from the average on the different domains of sexual function. Using this criterion, 71 men and 103 women from the original control sample were excluded from the study. The control sample was obtained between September 2000 and April 2002 and the participation rate was $30.6 \%$.

The demographic characteristics of the groups are shown in Table 1. Statistically significant differences were found between the clinical and control groups on the demographic variables of marital status in the women sample, $\chi^{2}(2)=$ $17.61, p<.001$, and education in both the women, $\chi^{2}(2, N=$ $207)=11.56, p<.01$, and the men, $\chi^{2}(2, N=169)=64.74$, $p<.001$. No significant differences were found for age.

\section{Procedure}

Participants from the clinical sample were recruited among the patients of the sexology clinic of Coimbra's University Hospital (an outpatient clinic of a central hospital serving the population of Coimbra and its region). Patients who were given a DSM-IV-TR diagnosis of sexual dysfunction (after completing a clinical assessment conducted by a group of trained sex therapists from the clinic using an unpublished structured interview for sexual dysfunctions) were approached about the study by a member of the research team and given an option to decline. An explanation of the purpose of the study was provided and a consent form was signed. Participants then answered the questionnaires by themselves in a private space and returned it directly to the member of the team. Participants took $40 \mathrm{~min}$ on average to answer the questionnaires.

Participants from the control sample were recruited in different regions of Portugal by a group of volunteer students 
from Universidade de Trás-os-Montes e Alto Douro. This group of students collected the sample in their hometowns throughout the country using non-random methods. Participants were contacted directly by the volunteers who explained the purpose of the study and gave them the questionnaire with the instructions (see Appendix). These subjects were instructed to answer the questionnaires when alone and in the privacy of their homes and then to return them by mail using pre-stamped envelopes. Subjects were not paid for their participation.

\section{Measures}

\section{The International Index of Erectile Function (IIEF)}

The IIEF (Rosen et al., 1997) is a 15-item self-administered measure assessing different areas of sexual functioning in men. A principal component analysis identified five factors: erectile function, orgasmic function, sexual desire, intercourse satisfaction, and overall satisfaction. Psychometric studies supported the reliability and discriminant validity of the measure. Studies with clinical samples demonstrated its sensitivity and specificity for detecting treatment related changes. The measure allows the calculation of specific indexes for each dimension as well as a sexual function total index (calculated through the sum of the specific dimensional indexes), with higher scores indicating greater levels of sexual functioning (sexual desire: $2-10$; erectile function: 1-30; orgasmic function: $0-10$; intercourse satisfaction: $0-15$; overall satisfaction: $2-10$; total: $5-75$ ).

\section{The Female Sexual Function Index (FSFI)}

The FSFI (Rosen et al., 2000) is a 19-item instrument, easily administered and scored, providing detailed information on several dimensions of sexual function. A principal component analysis identified six factors: sexual interest/desire, sexual arousal, lubrication, orgasm, sexual satisfaction, and sexual pain. The measure presents acceptable test-retest reliability, internal consistency, and validity. The measure allows the calculation of specific indexes as well as sexual function index (calculated through the sum of the specific dimensional indexes), with higher scores indicating greater levels of sexual functioning (sexual desire: 1.2-6; sexual arousal: 0-6; lubrication: 0-6; orgasm: 0-6; pain: 0-6; sexual satisfaction: $0.8-6$; total, $2-36$ ).

\section{Sexual Modes Questionnaire (SMQ)}

The SMQ (Nobre \& Pinto-Gouveia, 2000) is a measure aimed at assessing automatic thoughts, emotions, and sexual response during sexual activity. The questionnaire is composed of three subscales: Automatic thought subscale (AT), Emotional response subscale (ER), and Sexual response subscale (SR). The AT subscale is composed of 30 items (male version) or 33 items (female version) that assess automatic thoughts and images presented by the subjects during sexual activity. We asked participants to rate the frequency (from $1=$ never to $5=$ always) with which they usually experience those automatic thoughts during their sexual activity. A principal component analysis identified six factors in the female version: Sexual Abuse Thoughts, Failure and Disengagement Thoughts, Partner's Lack of Affection, Sexual Passivity and Control, Lack of Erotic Thoughts, and Low Self-Body-Image Thoughts; and five factors in the male version: Failure Anticipation Thoughts, Erection Concern Thoughts, Age Related Thoughts, Negative Thoughts Toward Sex, and Lack of Erotic Thoughts.

The ER subscale is composed of 30 items (male version) and 33 items (female version) that evaluate emotions reported by the subjects during sexual activity. The items are directly connected to the items of the AT subscale. So, for each automatic thought, participants indicated their emotional response. A list of 10 emotions was presented (worry, sadness, disillusion, fear, guilt, shame, anger, hurt, pleasure, satisfaction) and participants were asked to check which of them are usually experienced whenever they endorsed each automatic thought (see Appendix). An index for each emotional response was calculated based on the formula: (total number of each emotion endorsed/total number of emotions endorsed). For example, if a man checked 10 times the emotion worry, and in total checked 30 different emotions in response to the list of automatic thoughts, the index of worry for that case was 0.3 . The indexes based on this formula represent the proportion in which subjects usually experienced each emotion in response to automatic thoughts during sexual activity. The emotional response indexes ranged from 0 to 1 .

The SR subscale is composed of 30 items (male version) and 33 items (female version) assessing subjective sexual response during sexual activity. The items were directly connected to the items of the AT scale. So, for each automatic thought presented, the participants were asked to rate the intensity of their subjective sexual arousal (from $1=$ very low to $5=$ very high).

Psychometric studies have supported the reliability and validity of the SMQ (Nobre \& Pinto-Gouveia, 2003b). Testretest data indicated a statistically significant correlation $(r=.95, p<.01)$ for the total scale of the female version $(n=23)$ between two consecutive administrations with a 4week interval, and a moderate correlation $(r=.65, p<.05)$ for the male version (possibly due to the low sample size, $n=9$ ). Cronbach's alpha of .88 for the male and .87 for the female version supported the internal consistency of both scales. Convergent validity indicated that some emotions 
of the ER subscales were strongly associated with measures of sexual functioning. The FSFI correlated negatively with the emotional responses of sadness $(p<.01)$, guilt $(p<.01)$, and anger $(p<.05)$, and positively with pleasure $(p<.01)$. Similarly, the IIEF correlated negatively with sadness $(p<.01)$ and disillusion $(p<.01)$, and positively with pleasure $(p<.01)$ and satisfaction $(p<.01)$.

\section{Results}

Emotional response during sexual activity and sexual dysfunction in women

A 2 (Group: Sexually Dysfunctional vs. Sexually Functional) $\times 10$ (Emotional Response) multivariate analysis of covariance (MANCOVA), with age and marital status co-varied, yielded a significant multivariate effect for Group, $F(10$, $165)=4.49, p<.001$ (Wilks' Lambda $=0.79)$. Since the effects of the demographic variables of age and marital status on the dependent variables were statistically significant (age: Wilks' Lambda $=0.102, F(410,2102)=1.35, p<.001$; marital status: Wilks' Lambda $=0.807, F(30,720)=1.82$, $p<.01$ ), a decision was made to include them in the analysis as covariates.

Table 2 shows that sexually dysfunctional women reported, on average, significantly higher scores on the emotional responses of sadness $(p<.01)$, disillusion $(p<.05)$, guilt $(p<.001)$, and anger $(p<.05)$, compared to controls. On the other hand, the control group had, on average, significantly higher scores on the emotional responses of pleasure and satisfaction in response to automatic thoughts during sexual activity, compared to women with sexual dysfunction (both $p s<.001$ ). [It is important to note the moderate effect size of the differences, mainly regarding the emotional

Table 2 Indexes of female emotional response as a function of group (clinical group/control group)

\begin{tabular}{|c|c|c|c|c|c|c|c|}
\hline \multirow[b]{3}{*}{ Emotional response } & \multicolumn{4}{|c|}{ Group } & \multirow[b]{3}{*}{$F(1,174)$} & \multirow[b]{3}{*}{$p$} & \multirow[b]{3}{*}{$\eta^{2}$} \\
\hline & \multicolumn{2}{|c|}{$\begin{array}{l}\text { Clinical } \\
(n=46) \\
\end{array}$} & \multicolumn{2}{|c|}{$\begin{array}{l}\text { Control } \\
(n=132)\end{array}$} & & & \\
\hline & $\bar{M}$ & $S D$ & $\bar{M}$ & $S D$ & & & \\
\hline Worry & .17 & .14 & .18 & .14 & $<1$ & $n s$ & .002 \\
\hline Sadness & .18 & .10 & .12 & .11 & $11.15^{* *}$ & .001 & .060 \\
\hline Disillusion & .12 & .09 & .08 & .09 & $4.36^{*}$ & .038 & .024 \\
\hline Fear & .07 & .09 & .05 & .07 & 3.19 & $n s$ & .018 \\
\hline Guilt & .06 & .07 & .02 & .04 & $14.78^{* * *}$ & $<.001$ & .078 \\
\hline Shame & .04 & .07 & .04 & .06 & $<1$ & $n s$ & .003 \\
\hline Anger & .10 & .09 & .07 & .09 & $4.10^{*}$ & .045 & .023 \\
\hline Hurt & .05 & .06 & .04 & .06 & 2.33 & $n s$ & .013 \\
\hline Pleasure & .10 & .11 & .21 & .16 & $19.00^{* * *}$ & $<.001$ & .098 \\
\hline Satisfaction & .11 & .11 & .20 & .13 & $15.17^{* * *}$ & $<.001$ & .080 \\
\hline
\end{tabular}

Note. Absolute range, 0.0-1.0. responses of pleasure, satisfaction, and guilt (eta squared between .08 and .10)].

In order to examine the contribution of each emotional response to distinguish sexually functional from dysfunctional women, a discriminant analysis was performed. The ten indexes of the emotional response subscale and the demographic variables of age and marital status (in order to control their effects) were used as discriminant variables and sexual functioning as the criterion variable. The discriminant analysis produced a statistically significant function, Wilks' Lambda $=0.740, \chi^{2}(11)=51.30, p<.001$, confirming that the emotional response to automatic thoughts presented during sexual activity significantly differentiated sexually dysfunctional from functional women. A canonical correlation coefficient of .51 between the linear combination of the discriminant variables and the criterion variable indicated a strong discriminating power for the function.

The analysis of the individual contribution of each emotional response in discriminating clinical and control groups indicated that pleasure $(r=-.57)$, guilt $(r=.52)$, satisfaction $(r=-.48)$, and sadness $(r=.42)$ were the best predictors of group membership (see Table 3). Positive emotions (pleasure and satisfaction) had negative correlations with the discriminant function, whereas negative emotions had positive correlations, indicating that the discriminant function was mainly characterized by emotional negativity. The mean scores of both groups (clinical $=.99$, control $=-.35$ ) in the discriminant function showed the negative emotional response presented by sexually dysfunctional women during sexual activity.

The classification analysis indicated that $73 \%$ of the cases were correctly classified by the discriminant function $(71.7 \%$ in the clinical group and $73.5 \%$ in the control group), confirming the power of the emotional response during sexual activity in discriminating women with and without sexual dysfunction.

Table 3 Correlations between the indexes of female emotional response and the discriminant function scores $(n=207)$

\begin{tabular}{lr}
\hline & Discriminant function \\
\hline Pleasure & -.574 \\
Guilt & .521 \\
Satisfaction & -.477 \\
Sadness & .420 \\
Marital status & .388 \\
Anger & .265 \\
Disillusion & .262 \\
Fear & .229 \\
Hurt & .160 \\
Shame & .091 \\
Worry & -.060 \\
Age & -.008 \\
\hline
\end{tabular}

Note. Variables ordered by size of correlation within function. 
Emotional response during sexual activity and sexual dysfunction in men

A 2 (Group: Sexually Dysfunctional vs. Sexually Functional) $\times 10$ (Emotional Response) multivariate analysis of covariance (MANCOVA), with age, marital status, and education co-varied, yielded a significant multivariate effect for Group, $F(10,130)=3.10, p<.01$ (Wilks' Lambda $=0.81)$. Since the effects of the demographic variables of age, marital status, and education on the dependent variables were statistically significant (age: Wilks' Lambda $=0.012$, $F(530,1182)=1.26, \quad p<.01$; marital status: Wilks' Lambda $=0.547, F(50,760)=2.15, p<.001$; education: Wilks' Lambda $=0.535, F(60,859)=1.82, p<.001)$, a decision was made to include them in the analysis as covariates.

Table 4 shows that sexually dysfunctional men had significantly higher scores on the emotional responses of sadness $(p<.05)$, disillusion $(p<.05)$, and fear $(p<.05)$, and significantly lower scores on pleasure $(p<.001)$ and satisfaction $(p<.01)$. The effect size of the differences was generally small, with the exception of pleasure (eta squared $=.10$ ).

The discriminant analysis, using the ten indexes of the emotional response subscale and the demographic variables of age, marital status, and education (in order to control their effects) as discriminant variables and sexual functioning as the criterion variable, produced a statistically significant function (Wilks' Lambda $=0.444, \chi^{2}(12)=110.37$, $p<.001$ ), confirming that the emotional response to automatic thoughts presented during sexual activity significantly differentiated sexually dysfunctional from functional men. A canonical correlation coefficient of .75 between the linear combination of the discriminant variables and the criterion variable indicated a strong discriminating power for the function.

Table 4 Indexes of male emotional response as a function of group (clinical group/control group)

\begin{tabular}{|c|c|c|c|c|c|c|c|}
\hline \multirow[b]{3}{*}{ Emotional response } & \multicolumn{4}{|c|}{ Group } & \multirow[b]{3}{*}{$F(1,139)$} & \multirow[b]{3}{*}{$p$} & \multirow[b]{3}{*}{$\eta^{2}$} \\
\hline & \multicolumn{2}{|c|}{$\begin{array}{l}\text { Clinical } \\
(n=45)\end{array}$} & \multicolumn{2}{|c|}{$\begin{array}{l}\text { Control } \\
(n=99)\end{array}$} & & & \\
\hline & $\bar{M}$ & $S D$ & $\bar{M}$ & $S D$ & & & \\
\hline Worry & .25 & .21 & .23 & .18 & $<1$ & $n s$ & .005 \\
\hline Sadness & .19 & .20 & .06 & .09 & $5.43^{*}$ & .021 & .038 \\
\hline Disillusion & .16 & .18 & .08 & .09 & $4.68^{*}$ & .032 & .033 \\
\hline Fear & .09 & .14 & .06 & .09 & $6.08^{*}$ & .015 & .042 \\
\hline Guilt & .03 & .08 & .03 & .05 & $<1$ & $n s$ & .007 \\
\hline Shame & .04 & .06 & .03 & .06 & 1.11 & $n s$ & .008 \\
\hline Anger & .04 & .08 & .04 & .08 & $<1$ & $n s$ & .003 \\
\hline Hurt & .03 & .06 & .03 & .07 & $<1$ & $n s$ & .000 \\
\hline Pleasure & .08 & .09 & .25 & .20 & $15.57^{* * *}$ & $<.001$ & .101 \\
\hline Satisfaction & .08 & .10 & .18 & .17 & $7.11^{* *}$ & .009 & .049 \\
\hline
\end{tabular}

Note. Absolute range, 0.0-1.0.
Table 5 Correlations between the indexes of male emotional response and the discriminant function scores $(n=169)$

\begin{tabular}{lc}
\hline & Discriminant function \\
\hline Education & -.826 \\
Pleasure & -.421 \\
Sadness & .392 \\
Satisfaction & -.288 \\
Desillusion & .262 \\
Fear & .142 \\
Marital status & .131 \\
Age & .099 \\
Shame & .086 \\
Guilt & .038 \\
Worry & .038 \\
Anger & -.011 \\
Hurt & -.003 \\
\hline
\end{tabular}

Note. Variables ordered by size of correlation within function.

The analysis of the individual contribution of each emotional response in discriminating clinical and control groups indicated that pleasure $(r=-.42)$ and sadness $(r=.39)$ were the best predictors of group membership (see Table 5). It is noteworthy that education was by far the best predictor of group membership $(r=-.83)$, showing attention to the fact that men in the control group were significantly more educated than men in the clinical group. It is interesting to note that, while positive emotions (pleasure and satisfaction) presented negative correlations with the discriminant function, negative emotions (with the exception of anger and hurt) showed positive correlations, indicating that the discriminant function was mainly characterized by emotional negativity. As expected, the mean scores of the clinical group on the discriminant function (1.65) were in contrast to the mean scores of the control group (-.75), showing that sexually dysfunctional men had higher negative emotions associated with automatic thoughts during sexual activity.

The classification analysis indicated that $90.3 \%$ of the cases were correctly classified by the discriminant function (93.3\% in the clinical group and $88.9 \%$ in the control group). This finding supports the strong power of the emotional response during sexual activity to discriminate between men with and without sexual dysfunction.

\section{Discussion}

The purpose of the present study was to assess the emotional reactions to a list of automatic thoughts presented to sexually functional and dysfunctional men and women during sexual activity. Data supported the important role played by emotional response on sexual dysfunctional processes. The results showed that both men and women with sexual dysfunction endorsed significantly more negative emotions and 
less positive emotions to a list of automatic thoughts during sexual activity. Men with sexual dysfunction had significantly more emotions of sadness, disillusion, and fear and less pleasure or satisfaction compared to sexually healthy men. Female data pointed to similar differences, with women with sexual dysfunction reporting less pleasure and satisfaction, and more sadness, disillusion, guilt, and anger.

These data appear consistent with recent research on the role of emotions in sexual functioning. Namely, emotions related to depressed affect (sadness, disillusion, lack of pleasure, lack of satisfaction) seem to have a negative impact on sexual response (Beck \& Barlow, 1986; Heiman, 1980; Heiman \& Rowland, 1983; Koukounas \& McCabe, 2001; Meisler \& Carey, 1991; Mitchell et al., 1998; Nobre et al., 2003; Rowland et al., 1995, 1996).

Although research on the impact of emotions on sexual response is not yet extensive, a certain tendency to emphasize the role of emotions associated with lack of positive affect (depressed mood) as opposed to negative emotions (mostly related to anxiety) on sexual dysfunction seems to emerge. The neutral or even facilitator role of anxiety on sexual response is supported by empirical data (Barlow et al., 1983; Elliot \& O’Donohue, 1997; Laan et al., 1993; Palace \& Gorzalka, 1990).

Using the emotional typology of Watson et al. (1988) regarding positive and negative affect and the findings from Nobre et al. (2003), we may hypothesize that emotions usually associated with depressive disorders (lack of positive affect), as opposed to emotions related to anxiety disorders (negative affect), are most strongly associated with sexual dysfunction. The processes underlying the effect of the lack of positive emotions on sexual function are still unknown. However, recent research (Nobre, 2003; Nobre \& Pinto-Gouveia, 2003a, 2003b) indicating that men and women with sexual dysfunction present cognitive patterns similar to the ones observed in depressive disorders (e.g., incompetence schemas, failure anticipation thoughts, catastrophizing negative consequences, lack of positive thoughts) suggests a cognitive-emotional interference similar to the one observed in depression (Beck, 1996).

In fact, research on the role of different cognitive dimensions in sexual function based on Beck's modes model have indicated that men and women with sexual dysfunction activate significantly more incompetence self-schemas ("I'm incompetent," "I'm a failure") whenever they experience an unsuccessful sexual situation. These self-critical schemas, once activated, elicit negative automatic thoughts (failure anticipation thoughts and erection concern thoughts in men, and disengagement thoughts and sexual abuse thoughts in women) that prevent them from focusing on erotic stimuli (lack of erotic thoughts) and promote lack of positive emotions (sadness, disillusion, guilt, and lack of pleasure and satisfaction) (Nobre, 2003; Nobre \& Pinto-Gouveia, 2003b).
Results from the present study should, however, be interpreted with caution due to several limitations. One main limitation regards the use of a sample partially used in the validation studies of the SMQ (Nobre \& Pinto-Gouveia, 2003b). The clinical sample was identical in both studies, and part of the current control sample was also used in the validation study. Additional replications of the study using different samples should be conducted in order to verify its findings. Another possible limitation was the heterogeneity of the clinical sample. In fact, men and women from the clinical sample had diverse sexual complaints, and it is possible that there is some specificity in the emotional response according to different clinical diagnoses. As an example Rowland, Tai, and Slob (2003) found embarrassment and guilt to be the most common emotions reported by men with premature ejaculation during their sexual interactions. The fact that we did not control for the effect of psychopathology (e.g., depression, anxiety) is also a limitation, since clinical data suggest higher prevalence of depression and anxiety disorder in individuals with sexual dysfunction.

Another important issue was the way emotions were assessed in the study. In contrast to other studies, we assessed emotional responses to a list of automatic thoughts that may occur during sexual activity. We did not simply assess emotions endorsed in sexual situations, but emotions aroused by cognitions. Although this is consistent with a cognitive theoretical approach, findings should be interpreted with caution since they do not concern only emotional states but to the association between cognitions and emotions.

Overall, data on emotional responses showed a certain uniformity in men and women. These findings might have important implications both conceptually and clinically. Emotions associated with depressive mood and not with anxiety appear to be most strongly associated with sexual dysfunction; thus, treatment approaches oriented to reduce anxiety (relaxation and systematic desensitization) might be less efficient than interventions aimed at elevating mood during sexual activity. Research comparing these two therapeutic strategies would be very valuable in testing this hypothesis.

Acknowledgments This research is part of a doctoral dissertation presented by the first author to Faculdade de Psicologia e Ciências da Educação da Universidade de Coimbra, Coimbra, Portugal. The study was partially supported by a grant from PRODEP. The authors would like to thank to Allen Gomes, M. D., Hospitais da Universidade de Coimbra, Portugal, for making possible the collection of the clinical sample and also for his comments and suggestions. Thanks also to D. Rijo, M. A., C. Salvador, M. A., M. Lima, Ph.D., Faculdade de Psicologia, Universidade de Coimbra, Portugal; A. Gomes, M. A., L. Fonseca, M. A., A. Carvalheira, M. A., J. Teixeira, M. D., G. Santos, M. D., J. Quartilho, M. D., Ph.D., P. Abrantes, M. D., A. Canhão, M. D., Hospitais da Universidade de Coimbra, for their suggestions and help in sample collection. Thanks also to participants who volunteered to participate in the study. 


\section{APPENDIX: Sexual Modes Questionnaire (SMQ; P. Nobre \& Pinto-Gouveia, 2000)}

The items presented below are a list of thoughts one can have during sexual activity. In the first column, please indicate the frequency of which you experience these thoughts by circling a number (1-never to 5-always). Next, indicate the types of emotions you typically experience when having these thoughts by marking an $\mathrm{X}$ in the columns for the appropriate emotions. Finally, in the last column, for each thought experienced indicate the intensity of your typical sexual response (arousal) while you are having that thought by circling a number (1-very low to 5 -very high).

NOTE: For thoughts that you indicate as never experiencing, you do not need to fill out the emotion or sexual response column.

\section{MALE ITEM EXAMPLES}

\begin{tabular}{|c|c|c|c|c|c|c|c|c|c|c|c|c|c|c|c|c|c|c|c|}
\hline \multicolumn{5}{|l|}{ THOUGHTS } & \multicolumn{10}{|c|}{ EMOTIONS } & \multicolumn{5}{|c|}{\begin{tabular}{|c|} 
SEXUAL \\
RESPONSE
\end{tabular}} \\
\hline & \multicolumn{4}{|c|}{ FREQUENCY } & \multicolumn{10}{|c|}{ TYPES OF EMOTIONS } & \multicolumn{5}{|c|}{ INTENSITY } \\
\hline TYPE OF THOUGHTS & 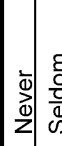 & 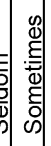 & & & 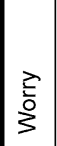 & $\begin{array}{l}\infty \\
0 \\
\infty \\
\stackrel{5}{0} \\
\frac{0}{0} \\
\infty \\
\infty\end{array}$ & 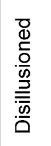 & 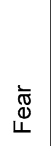 & 奇 & $\begin{array}{l}\frac{\mathscr{E}}{\Phi} \\
\frac{\mathbb{T}}{\omega}\end{array}$ & $\begin{array}{l}\bar{d} \\
\stackrel{\Xi}{\leftarrow}\end{array}$ & $\stackrel{5}{5}$ & 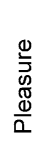 & 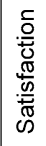 & $\begin{array}{l}3 \\
\text { 의 } \\
\stackrel{0}{0} \\
>\end{array}$ & కృ & $\begin{array}{l}\frac{0}{\pi} \\
\frac{\pi}{0} \\
\frac{0}{2} \\
\frac{0}{2}\end{array}$ & & \\
\hline This time I cannot disappoint my partner & \begin{tabular}{|l|l|l}
1 & 2 \\
\end{tabular} & 3 & 4 & 5 & & & & & & & & & & & & 2 & 3 & 4 & 5 \\
\hline I must be able to have intercourse & \begin{tabular}{l|l}
1 & 2 \\
\end{tabular} & 3 & 4 & 5 & & & & & & & & & & & 1 & 2 & 3 & 4 & 5 \\
\hline I'm not satisfying her & \begin{tabular}{l|l}
1 & 2 \\
\end{tabular} & 3 & \begin{tabular}{|l|l|l}
4 & \\
\end{tabular} & 5 & & & & & & & & & & & 1 & 2 & 3 & 4 & 5 \\
\hline I must achieve an erection & \begin{tabular}{l|l|l}
1 & 2 \\
\end{tabular} & 3 & \begin{tabular}{|l|l|l}
4 & \\
\end{tabular} & 5 & & & & & & & & & & & 1 & 2 & 3 & 4 & 5 \\
\hline Why isn't this working? & \begin{tabular}{|l|l|}
1 & 2 \\
\end{tabular} & 3 & 4 & 5 & & & & & & & & & & & 1 & 2 & 3 & 4 & 5 \\
\hline What is she thinking about me? & \begin{tabular}{|l|l|l}
1 & 2 \\
\end{tabular} & 3 & $4 \mid$ & 5 & & & & & & & & & & & 1 & 2 & 3 & 4 & 5 \\
\hline What if others knew I'm not capable... & \begin{tabular}{|l|l|l}
1 & 2 \\
\end{tabular} & 3 & \begin{tabular}{|l|l|l}
4 & \\
\end{tabular} & 5 & & & & & & & & & & & 1 & 2 & 3 & 4 & 5 \\
\hline If I fail again I am a lost cause & \begin{tabular}{l|l}
1 & 2 \\
\end{tabular} & 3 & 4 & 5 & & & & & & & & & & & 1 & 2 & 3 & 4 & 5 \\
\hline This is turning me on & \begin{tabular}{l|l}
1 & 2 \\
\end{tabular} & 3 & 4 & 5 & & & & & & & & & & & 1 & 2 & 3 & 4 & 5 \\
\hline She is not being as affectionate as she used to & \begin{tabular}{l|l}
1 & 2 \\
\end{tabular} & 3 & 4 & 5 & & & & & & & & & & & 1 & 2 & 3 & 4 & 5 \\
\hline She is really turned on & \begin{tabular}{l|l}
1 & 2 \\
\end{tabular} & 3 & $4 \mid$ & 5 & & & & & & & & & & & 1 & 2 & 3 & 4 & 5 \\
\hline It will never be the same again & \begin{tabular}{|l|l|l}
1 & 2 \\
\end{tabular} & 3 & 4 & 5 & & & & & & & & & & & 1 & 2 & 3 & 4 & 5 \\
\hline If I can't get an erection, I will be embarrassed & \begin{tabular}{l|l}
1 & 2 \\
\end{tabular} & 3 & \begin{tabular}{|l|l}
4 & \\
\end{tabular} & 5 & & & & & & & & & & & 1 & 2 & 3 & 4 & 5 \\
\hline
\end{tabular}

FEMALE ITEM EXAMPLES

\begin{tabular}{|c|c|c|c|c|c|c|c|c|c|c|c|c|c|c|c|c|c|}
\hline \multicolumn{5}{|l|}{ THOUGHTS } & \multicolumn{10}{|c|}{ EMOTIONS } & \multirow{2}{*}{\multicolumn{3}{|c|}{\begin{tabular}{|c|}
$\begin{array}{c}\text { SEXUAL } \\
\text { RESPONSE }\end{array}$ \\
INTENSITY \\
\end{tabular}}} \\
\hline \multirow[t]{2}{*}{ TYPE OF THOUGHTS } & \multicolumn{4}{|c|}{ FREQUENCY } & \multicolumn{10}{|c|}{ TYPE OF EMOTIONS } & & & \\
\hline & 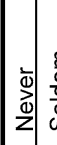 & 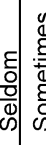 & है: & - & ڤ̀) & $\begin{array}{l}0 \\
\mathscr{8} \\
\stackrel{0}{0} \\
\frac{0}{0} \\
\infty\end{array}$ & 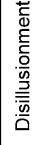 & $\begin{array}{l}\stackrel{\bar{\Phi}}{\Phi} \\
\stackrel{\perp}{L}\end{array}$ & 壹 & $\begin{array}{l}\stackrel{0}{E} \\
\frac{\tilde{\pi}}{\infty} \\
\frac{\tilde{\omega}}{2}\end{array}$ & $\begin{array}{l}\grave{\Xi} \\
\stackrel{\Xi}{<}\end{array}$ & 壱 & $\begin{array}{l}\frac{\Phi}{\square} \\
\frac{D}{0} \\
\frac{0}{0} \\
\frac{\omega}{\alpha}\end{array}$ & 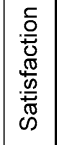 & 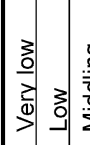 & 흘 & 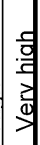 \\
\hline He is abusing me & & & & & & & & & & & & & & & & & \\
\hline How can I get out of this situation? & & & & & & & & & & & & & & & & & \\
\hline He only wants to satisfy himself & & & & & & & & & & & & & & & & & \\
\hline The way he is talking turns me on & & & & & & & & & & & & & & & & & \\
\hline This way of having sex is immoral & & & & & & & & & & & & & & & & & \\
\hline I'm getting fat/ugly & & & & & & & & & & & & & & & & & \\
\hline Making love is wonderful & & & & & & & & & & & & & & & & & \\
\hline He is not being as affectionate as he used to be & & & & & & & & & & & & & & & & & \\
\hline I'm not satisfying my partner & & & & & & & & & & & & & & & & & \\
\hline This is disgusting & & & & & & & & & & & & & & & & & \\
\hline I'm not as physically attractive as I used to be & & & & & & & & & & & & & & & & & \\
\hline I'm not getting turned on & & & & & & & & & & & & & & & & & \\
\hline When will this be over? & & & & & & & & & & & & & & & & & \\
\hline
\end{tabular}




\section{References}

American Psychiatric Association. (2000). Diagnostic and statistical manual of mental disorders (4th ed., text rev.). Washington, DC: Author.

Bancroft, J., Janssen, E., Strong, D., Carnes, L., Vukadinovic, Z., \& Long, S. (2003). The relation between mood and sexuality in heterosexual men. Archives of Sexual Behavior, 32, 217-230.

Barlow, D. H., Sakheim, D. K., \& Beck, J. G. (1983). Anxiety increases sexual arousal. Journal of Abnormal Psychology, 92, 49-54.

Beck, A. T. (1996). Beyond belief: A theory of modes, personality and psychopathology. In P. M. Salkovskis (Ed.), Frontiers of cognitive therapy (pp. 1-25). New York: Guilford Press.

Beck, J. G., \& Barlow, D. H. (1986). The effects of anxiety and attentional focus on sexual responding-II: Cognitive and affective patterns in erectile dysfunction. Behaviour Research and Therapy, $24,19-26$.

Beck, J. G., Barlow, D. H., Sakheim, D. K., \& Abrahamson, D. J. (1987). Shock threat and sexual arousal: The role of selective attention, thought content, and affective states. Psychophysiology, $24,165-172$

Bozman, M. A., \& Beck, J. G. (1991). Covariation of sexual desire and sexual arousal: The effects of anger and anxiety. Archives of Sexual Behavior, 20, 47-60.

Cappelleri, J. C., Rosen, R. C., Smith, M. D., Mishra, A., \& Osterloh, I. H. (1999). Diagnostic evaluation of the erectile function domain of the International Index of Erectile Function. Urology, 54, $346-351$

Elliot, A. N., \& O'Donohue, W. T. (1997). The effects of anxiety and distraction on sexual arousal in a nonclinical sample of heterosexual women. Archives of Sexual Behavior, 26, 607-624.

Heiman, J. R. (1980). Female sexual response patterns: Interactions of physiological, affective, and contextual cues. Archives of General Psychiatry, 37, 1311-1316.

Heiman, J. R., \& Rowland, D. L. (1983). Affective and physiological sexual response patterns: The effects of instructions on sexually functional and dysfunctional men. Journal of Psychosomatic Research, 27, 105-116.

Hoon, P., Wincze, J. P., \& Hoon, E. (1977). A test of reciprocal inhibition: Are anxiety and sexual arousal in women mutually inhibitory? Journal of Abnormal Psychology, 86, 65-74.

Kaplan, H. S. (1974). The new sex therapy. New York: Brunner/Mazel.

Katz, R. C., \& Jardine, D. (1999). The relationship between worry, sexual aversion, and low sexual desire. Journal of Sex and Marital Therapy, 25, 293-296.

Koukounas, E., \& McCabe, M. P. (2001). Sexual and emotional variables influencing sexual response to erotica: A psychophysiological investigation. Archives of Sexual Behavior, 30, 393-408.

Laan, E., Everaerd, W., Van-Aanhold, M., \& Rebel, M. (1993). Performance demand and sexual arousal in women. Behaviour Research and Therapy, 31, 25-35.

Masters, W. H., \& Johnson, V. E. (1970). Human sexual inadequacy. Boston: Little, Brown.

Meisler, A. W., \& Carey, M. P. (1991). Depressed affect and male sexual arousal. Archives of Sexual Behavior, 20, 541-554.

Meston, C. M., \& Gorzalka, B. B. (1996). Differential effects of sympathetic activation on sexual arousal in sexually dysfunctional and functional women. Journal of Abnormal Psychology, 105, 582591.
Mitchell, W. B., DiBartolo, P. M., Brown, T. A., \& Barlow, D. H. (1998). Effects of positive and negative mood on sexual arousal in sexually functional males. Archives of Sexual Behavior, 27, 197-207.

Nobre, P. J. (2003). Sexual dysfunction: Contributions for the construction of a comprehensive model based on cognitive theory. Unpublished doctoral dissertation. Faculdade de Psicologia e Ciências da Educação da Universidade de Coimbra, Coimbra, Portugal.

Nobre, P. J., \& Pinto-Gouveia, J. (2000). Sexual modes questionnaire $(S M Q)$. Unpublished manuscript.

Nobre, P. J., \& Pinto-Gouveia, J. (2003a). Cognitive Schema Activation in Sexual Context: A questionnaire to assess cognitive schemas activated in sexual failure situations. Manuscript submitted for publication.

Nobre, P. J., \& Pinto-Gouveia, J. (2003b). Sexual modes questionnaire: Measure to assess the interaction between cognitions, emotions and sexual response. Journal of Sex Research, 40, 368382.

Nobre, P. J., \& Pinto-Gouveia, J. (2004). Differences in automatic thoughts presented during sexual activity between sexually functional and dysfunctional males and females. Manuscript submitted for publication.

Nobre, P. J., Wiegel, M., Bach, A., Weisberg, R., Brown, T., Wincze, J., et al. (2004). Determinants of sexual arousal and the accuracy of its self-estimation in sexually functional males. Journal of Sex Research, 41,, 363-371.

Palace, E. M. (1995). Modification of dysfunctional patterns of sexual response through autonomic arousal and false physiological feedback. Journal of Consulting and Clinical Psychology, 63, 604-615.

Palace, E. M., \& Gorzalka, B. B. (1990). The enhancing effects of anxiety on arousal in sexually functional and dysfunctional women. Journal of Abnormal Psychology, 99, 403-411.

Rosen, R. C., Brown, C., Heiman, J., Leiblum, S., Meston, C., Shabsig, R., et al. (2000). The Female Sexual Function Index (FSFI): A multidimensional self-report instrument for the assessment of female sexual function. Journal of Sex and Marital Therapy, 26, 191-208.

Rosen, R. C., Riley, A., Wagner, G., Osterloh, I. H., Kirkpatrck, J., \& Mishra, A. (1997). The International Index of Erectile Function (IIEF): A multidimensional scale for assessment of erectile dysfunction. Urology, 49, 822-830.

Rowland, D. L., Cooper, S. E., \& Heiman, J. R. (1995). A preliminary investigation of affective and cognitive response in men before and after treatment in a sex therapy program. Journal of Sex and Marital Therapy, 21, 3-20.

Rowland, D. L., Cooper, S. E., \& Slob, A. K. (1996). Genital and psychoaffective response to erotic stimulation in sexually functional and dysfunctional men. Journal of Abnormal Psychology, 105, 194-203.

Rowland, D. L., Tai, W. L., \& Slob, A. K. (2003). An exploration of emotional response to erotic stimulation in men with premature ejaculation: Effects of treatment with clomipramine. Journal of Abnormal Psychology, 105, 194-203.

Watson, D., Clark, L. A., \& Tellegen, A. (1988). Development and validation of brief measures of positive and negative affect: The PANAS scales. Journal of Personality and Social Psychology, 54, 1063-1070.

Yates, E. P., Barbaree, H., \& Marshall, W. L. (1984). Anger and deviant sexual arousal. Behavior Therapy, 15, 287-294. 